\title{
Bringing kinship into being: Connectedness, donor conception and lesbian parenthood
}

Petra Nordqvist, University of Manchester

Petra.Nordqvist@Manchester.ac.uk

Post peer-review version of article published in

Nordqvist, P (2014) 'Bringing kinship into being: Connectedness, donor conception and lesbian parenthood', Sociology, 48(2): 263 - 278. DOI:10.1177/0038038513477936

Please refer to the published version for citations.

This article draws on Petra's PhD research into lesbian couples' experiences of donor conception. For more information about other articles published by Petra about lesbian donor conception and assisted reproduction more broadly, please visit

http://www.manchester.ac.uk/research/petra.nordqvist/

Petra's most recent project 'Relative Strangers' (2010-2013) (with Carol Smart) explored the impact of donor conception on family life among heterosexual and lesbian couples. The research explored parents as well as grandparents' experiences of donor conception in their families. The findings from this project are available in the book 'Relative Strangers: Family Life, Genes and Donor Conception'. If you are interested in reading more about the project and see our videos, please visit http://www.socialsciences.manchester.ac.uk/morgancentre/our-research/kinship-andrelatedness/relative-strangers/ 


\title{
Bringing kinship into being: Connectedness, donor conception and lesbian parenthood
}

\section{Dr Petra Nordqvist, University of Manchester}

\begin{abstract}
The meaning of kinship received little sustained attention for some time in British sociology. However, we are now beginning to see a shift, and Jennifer Mason's (2008) conceptualisation of kinship affinities makes an important contribution to emerging debates. In this paper I seek to add to such debates and also provide original data from the field of donor conception and lesbian motherhood, a particularly rich field in which to explore the meaning of kin. I investigate stories about becoming parents, and demonstrate that the issue of bringing kinship into being is a key concern in that process. I develop the argument that kinship is a multilayered and malleable resource with an exceptional capacity to encompass difference. This leads me to suggest that we need to be sensitive to the multitude, shifting ways in which connectedness is experienced in personal life.
\end{abstract}

\section{Keywords}

Donor conception, kinship, lesbian, parenthood 


\section{Introduction}

Kinship and relatedness received little sustained attention for some time in British sociology. While the meaning of being related was a matter of sociological debates in the 1960 s and 1970s (e.g. Firth et al. 1970, Rosser and Harries 1965), it thereafter appeared to become rather less fashionable as an area of study. Also when many sociologists turned their gaze to exploring the changing patterns in family life and emerging notions of intimacy in the 1990s, this work focused predominantly on the shifts occurring within the nuclear family household, and not on the meaning of wider family networks. With some notable exceptions (e.g. Brannen et al 2004, Finch and Mason 1993, 2000) little attention was paid to relationships with wider kin. It appears that we are now, however, beginning to see a shift. Mason and Finch have taken their interest in kinship further as they respectively have explored the social role and fascination of kinship (Mason 2008), and the social meaning of family names (Finch 2008). Their work has also generated new interest and insights in kinship as illustrated in Davies (2011) exploring the role of surnames for children and in Kramer (2011) addressing the role of genealogical research in personal life. Alongside these studies, there is a growing focus on the meaning of being connected and the place of wider family, particularly associated with the work of Smart (2007) who suggests that connectedness is of central importance to the formation of personal life.

Mason's (2008) paper 'Tangible Affinities and the Real Life Fascination of Kinship' makes a particularly important theoretical contribution to these debates. She introduces a nuanced, multidimensional perspective on kinship affinities that allows us to recognise kinship beyond the more anthropological conceptual debates about the relationship between biogenetic and interpersonal kin, and she brings into view both tangible as well as more intangible understandings of affinities. Added to that, she makes the important observation that what constitutes kinship is something that is actively engaged in in everyday life and that kinship affinities come into play in intersecting ways 'when the distinctiveness of kinship and the criteria that constitute it are being settled upon. Through these dimensions, kinship is engaged with, defined, known and expressed' (2008: 42). Thus, she introduces a framework that alludes to a form or relatedness that is being worked through, defined and known within and through everyday life, rather than something given. 
In this paper I seek to build on and advance sociological theoretical frameworks of kinship and also provide original data from the field of donor conception and lesbian motherhood. By exploring women's stories about becoming parents, I develop the argument that kinship is a key concern in everyday life, and one that raises questions about how affinities are known and how they are brought into existence. I bring forward the idea that kinship is a relationship that is malleable and mutable in character and also a way of relating that can be brought to life in exceptionally complex and multilayered ways. I suggest that affinities can take a range of forms and shift over time, and yet still be seen and experienced as just that: kinship. I also propose that underlying engagements with kinship is a deep concern with being connected, and how to construct connectedness in everyday life. This leads me to suggest that we need to be sensitive to the multitude and shifting ways in which connectedness is known, how it can be brought into existence and carry meaning in everyday life.

Donor conception offers a particularly useful viewpoint from which to explore kinship. It transgresses taken-for-granted cultural idioms of blood and relatedness and as such it also brings to the fore the question of what it means to be related. Same sex couples, as well as single people and heterosexual couples pursuing donor conception find themselves in a process that raises questions about kin. This is not least the case because they must necessarily take decisions about who to use as their donor(s), how to make that decision and how to relate to him and/or her. In doing so they actively reflect on how relationships, affinities, belonging and kinship might matter in everyday life, and importantly, how they are activated and brought into existence. The ways in which women and men think explicitly about the creation of kinship affinities in the absence of normative biogenetic family bonds are indicative of how kinship affinities are imagined and perceived to be brought into existence in wider kinship discourse.

\section{Pursuing donor conception}

Assisted reproduction, of course, also highlights the uncertainties involved in human reproduction, and that the way in which one has one's children can be a process that is not necessarily within one's control. For many, the decision to resort to assisted reproduction and using donated gametes raises a number of questions; lesbian couples have to manage 
both the contribution of the donor (and potentially, father) as well as the socially unusual situation of there being two mothers.

Underlying these questions is a series of practical, physical and logistic dimensions that the process itself brings to the fore. Working out how to go about becoming pregnant entails making decisions about a number of interlinked stages (e.g. Dunne 2000, Luce 2010, Nordqvist 2011) and overcoming a series of hurdles. One such hurdle is of course the issue of accessing donor sperm. In the UK, and at the time of this research in 2007 and 2008, access to fertility services was regulated by the Human Fertilisation and Embryology Authority (HFEA) in conjunction with the National Institute for Health and Clinical Excellence (NICE) and, in the case of publicly funded treatment on the National Health Service (NHS), regionally by Primary Care Trusts (PCTs). The regulatory guidelines operating at the time followed the Human Fertilisation and Embryology Act 1990 requiring clinics to consider a child's need for a father. Additionally, NICE's (2004: 9) recommendations were for couples that struggled to conceive to have 'sexual intercourse every 2 to 3 days throughout the month', rendering lesbians invisible as conceiving agents. Failing to fall within NICE's criteria, lesbians would often not be deemed eligible for funded treatment on the NHS, and would have to resort to either self-funding treatment or self-arranging donor conception. For the couples in my study, the reproductive health centre represented an option only for couples with sufficient resources as only a small minority managed to negotiate access to treatment fully or partially funded by the NHS. A less common route was to use an Internet company that arranged the delivery of anonymous, fresh (as opposed to frozen) donor sperm. Selfarranged conception, i.e. informal arrangements with friends, acquaintances or strangers, remained for many however the only viable option.

It would however be wrong and too optimistic to assume that these couples were in complete command over their reproductive journey. Commonly, couples started pursuing their favoured option (be it clinical or self-arranged conception), but as time went by, different factors would push them in new directions. For example, a relationship with a donor might break down or a couple may run out of financial means to pay clinical fees. The route to conception became a complex interplay between practical, physical, material, logistic as well as interpersonal factors. Often the birth of a child would be the result of having considered, explored, pursued and failed at a series of avenues. For most couples in 
my study months, and sometimes years, of failed attempts and pathways preceded parenthood.

It is important to emphasise that as with any reproduction, these couples experienced a process which was in part shaped by their desires and wishes, and in part by issues beyond their control. As a result, their routes, desires and options changed with circumstance and with the way that their lives and conception journey 'worked out'. This, in turn, shaped the way in which they perceived and engaged in the process of bringing kinship into existence. Imagining kinship and the future family was a question revisited again and again with every new avenue explored.

\section{Alternative forms of reproduction: kinship and 'kinning'}

Sociologists have been slow to engage with the issue of assisted reproduction. Work in this area has instead been predominantly located in the field of psychology (e.g. Golombok and Badger 2010, Golombok et al 1997), social work (e.g. Daniels et al 1995, Blyth et al 2009), as well as in anthropology (e.g. Edwards 2000, Franklin 1997, Strathern 1992). With regards to kinship, the work of anthropologist Marilyn Strathern $(1992,1995)$ has been particularly influential. She (1992) argues that kinship is a social system that is rooted in constructions of both nature and society: both blood (nature) and marriage (choice) are fundamental to what we see as 'kin'. However, conceptual (blood) and interpersonal kinship should not be understood as mutually exclusive categories, but instead as dimensions that fold into one another, constituting 'tool[s] [...] for social living' (Strathern 2005: 7). Biogenetic and interpersonal kinship do not necessarily overlap, she argues, and choices are made about whether biogenetic kin connectedness is rendered meaningful or not (Strathern 1992 in Hayden 1995: 45). This importantly deconstructs the role of genetics in contemporary kinship thinking and introduces the idea that its meaning might be negotiated rather than given.

Anthropologists have also engaged with the issue of adoption and its consequences for kinship (e.g. Carsten 2004, Howell 2001). Melhuus and Howell (2009) argue that both donor conception and adoption transgress conventional kinship idioms based on blood and in that sense share the same cultural universe of 'unnatural' procreation. Exploring kinship in the context of international adoption, Howell (2001) importantly indicates that adoptive parents' attempts to transcend their lack of genetic connectedness to their child can be 
characterised as 'self-conscious' kinship. Parents are actively engaged in a process of creating family origin narratives that bring the adoptive children into meaningful connectedness with them and other relatives (Howell 2001: 206). They seek to 'enrol their adoptive children into a kinned trajectory that overlaps their own' through practices of 'kinning' (Howell 2003:466). The concepts 'kinning' and 'self-conscious kinship' provide useful frameworks for understanding the process whereby kinship is settled upon.

\section{The study}

I draw on a study into lesbian couples' experiences of donor conception conducted in England and Wales 2006-2009 that comprised 25 qualitative in-depth interviews with lesbian couples. As noted in previous studies of non-heterosexual intimate life, same-sex couples constitute a 'hidden' population and a hard-to-reach group; no sampling frame exists for their recruitment (Weeks et al. 2001). I therefore had to employ a purposive sampling method. I recruited lesbian couples through multiple gateways, both online and offline. The majority of couples (17) were recruited through five online chat rooms aimed at gays and lesbians at the time (www.gingerbeer.com, www.rainbownetwork.com, www.stonewall.org.uk, www.lgbtparents.probaords74.com, https://groups.msn.com/lesbianinseminationsupport). These generally had open access and discussion threads were publically available, thus minimising the role of gatekeepers in the research process. Eight further participants were recruited through offline networks, and also on social events aimed particularly at lesbians (e.g. the York Lesbian Arts Festival). Through this process, I openly stated my own sexual identity as lesbian, something that most likely will have assisted the recruitment process given the sensitivities that may exist around sexual identity and motherhood. The study was approved by the Centre for Women's Studies Ethics Committee, University of York, before fieldwork commenced. Securing the participants' confidentiality and anonymity were particularly important given said sensitivities; all identifying details were changed.

I conducted semi-structured, theme-based narrative interviews that explored planning conception; doing the insemination; and becoming and being a family. Couple interviews were conducted where possible, and altogether 45 women took part. All interviews were recorded and transcribed verbatim and the data were thematically analysed using a narrative-holistic approach (Lieblich et al. 1998). This was conducted using graphic 
elicitation and event-state networks which entailed constructing graphic 'maps' detailing the couples' routes to conception by marking events (e.g. met donor, visited clinic) and the motivations (e.g. feelings, desires) that made them happen (Miles and Huberman 1994).

The stories that I explore in-depth are illustrative of lesbians' reproductive journeys and also of the plethora of ways in which kinship might be imagined. I have selected these three in particular because they provide in-depth insight into the vicissitudes of donor conception and decisions about donors, whilst also highlighting the multilayered ways in which parents seek to enrol their children in kinned trajectories (Howell 2003). A case study approach allows me to explore these kinning processes in detail, but rather than being unusual in the study as a whole, they reflect concerns as well as practices emerging across the interviews. I have used a cross sectional analysis of the full data set in other writing exploring, e.g. family resemblances (Nordqvist 2010) and the meaning of biogenetic siblings (Nordqvist 2012a).

The women quoted from these cases were white, middle class couples, located in England (North, Middle and South) and in their thirties and early forties. In terms of the larger study, the median age was 33.5 and forty two women identified as white British, Welsh or English and three women identified as of mixed ethnic origin, Chinese British and Black British. Twelve couples in the sample had pursued donor conception through a licensed clinic while eleven had undertaken self-arranged conception (a further two were at a planning stage). Using highest educational qualification as an indication of social class (Graham 2007), a third of the women originated from working class backgrounds and two thirds from middle class backgrounds.

\section{Laying down connections}

Couples who use donor conception must necessarily engage with the idea that their family spans more than two parents and that the child is genetically connected beyond the couple. Exactly what having a donor means in terms of who forms part of the child's kinship network, however, is a rather open question. There is no straightforward answer as to who should be included in such a network, and why. The birth mother? The non-birth mother? The donor? The mothers' families? The donor's family? The donor's other offspring? What might such connections look like, and can they take various forms? In the following, I explore three stories about kinship connectedness and how it might be 'worked out' in 
different contexts. In conclusion I draw out some of the wider implications for the concept of kinship.

\section{Keeping it in the family}

The first case is a story of how a couple can understand and construe kinship with a focus on the lesbian mother family. Kim, 30 and Nicola, 41 were expecting their first child in the autumn of 2007; a child conceived using an anonymous (but identifiable) donor in a clinic. They had, however, started their process rather differently. They had a preference for selfarranging donation, and had planned to use a friend's sperm, who would also be a known as the child's father. By virtue of being the donor father, they saw him as having an important role in the child's life. They did not, however, want him to be an active parent as they feared that this might challenge the non-birth mother's place as such. Of course, there is no clear boundary between being a known father and being an involved parent, and after six months of negotiating the arrangement fell through, as the donor wanted involvement. This experience pushed the couple into using licensed, and unknown, donor sperm, echoing many other's experiences (Donovan and Wilson 2008). The process of accessing anonymised donor sperm afforded this couple more safely the opportunity of transform themselves into parents. Following Howell (2003: 482), the decision to access the clinic might be understood as a step that would enable the transformation of the subjectivity of both women as well as the child into one of kinship.

This shift did not however lessen the mothers' engagement in creating kinship, after all, such a concern had motivated them to involve a known donor in the first place. Interestingly, however, as a consequence of accessing the clinic, they also started to renegotiate the way in which connections could be brought into existence. Instead of focusing on the donor, their efforts in creating kinship bonds became exclusively focused on constructing such connections within the lesbian mother family.

This was illustrated in their donor selection process. Whereas the known donor had been chosen because he was a longstanding friend, the couple became preoccupied with choosing a donor who was most like the two mothers. Following Howell (2003) the couple tried to create a life trajectory for the child that overlapped their own, something that required a great deal of reflection. Finding a 'matching' donor is of course a salient and longstanding strategy to do so and is established clinical practice among heterosexual as well as 
lesbian couples (e.g. Nordqvist 2012b). Physical similarities carry forward family relations and as such they constitute a relational identity of kinship (Marre and Bestard 2009: 69f). But additionally, genes were instilled with meanings of aptitudes and personality (Almeling 2007). Kim, the birth mother, said:

We were trying to go for people whose physical characteristics were a bit similar to Nicola's. I mean, the guy who's the father of this child is... he's got brown hair and green eyes [laughter], you know. You know, he's like sporty, and Nicola's quite interested in sport.

I mean, something that would've been lovely, which in fact none of them [the donors] really were musical, were they? Because we're both musical. But then [the baby] is going to get so much music [through us]. [...] So, you know, it's going to be surrounded by music anyway and it will get musical genes from me, so it's okay.

Seeking to ensure a level of similarity between Nicola and the child they wanted a 'sporty' donor; construing 'being sporty' as something that might be genetically inherited. Their account, however, signals a rather flexible and almost playful approach to genetics and how bonds of kinship might be created. Being 'sporty' and being 'musical' could be attributed to genetics but it could also be created through practice and everyday life. In doing so, they moved quite freely between what Strathern (2005) has identified as conceptual (biogenetic) and interpersonal kinship. They considered genes and any genetic inheritability to be important, but equally important was the interpersonal relationality emerging within the couple's everyday life. Using both, kinship emerges as a relationship that was negotiated and engaged with (Mason 2008). The couple thus worked hard to identify what the ingredients of kinship might be, and what might be important to add to the 'mix'.

They approached the issue of siblinghood in an equally flexible manner, and with equal measures of reflection. On discovering that they were pregnant, they had bought additional sperm from the same donor for the conception of a sibling. Kim and Nicola valued the fixed affinity that this, in their minds, entailed, but without primarily attaching significance to the vertical genetic relationship between child and donor. Instead, doing so was associated with possibly strengthening the lateral social relationship between the siblings. Kim explains: 
[I]f it's two different fathers you can imagine the worst case scenario, the older child goes off to meet her father [...], and they get on really well and it's great and they build a relationship and it's fantastic; the younger child he gets to 18 , he goes to meet his father, different man, who says, I'm not interested. I don't want a relationship with you. I think that's really, potentially really difficult. [...] If he wants a relationship, and so do they, then they're both in that same situation.

Interestingly, the couple are not foremost concerned with the possible fixed affinity between the donor and child; what they are hoping to create are social affinities between the siblings. Choosing the same donor becomes a process of creating a shared life trajectory for both siblings. But Kim's account also echoes the idea that a sibling relationship should be shaped by equity and fairness, a discourse shaping social understandings of siblinghood (e.g. Lashewicz et al. 2007). Their concern here is not foremost with any possible future relationship with the donor, but in which this genetic relationship positions the siblings in an equal and fair way.

It is worth pausing for a moment to ponder on the criteria of kinship emerging from this account. What belief about kinship underscores their process? How is thought possible to bring it into existence? I want to suggest that the common denominator that frames their accounts about looks, aptitudes and siblinghood is the idea that sameness produces bonds and connections. They draw on a cultural framework in which a kinship relationship is believed to be formed through the reproduction of identity. Strathern writes:

Reproduction commonly means to bring into existence something that already exists in another form. [...] Euro-American understandings of the similarities involved in human reproduction are, of course, not at all neutral as to the nature of the relationship at issue. A relationship is thought to inhere in a continuity of (personal) identity. (1995: 354, my emphasis)

She goes on to note that reproduction is embedded in the transmittance of 'idioms of possession' (be it body parts or way of life) to the future (1995: 354). Kim and Nicola's attempts at bringing kinship into being draws on the idea that reproduction is entailed in the continuity of personal identity, brought together in a mixture of genes, aptitudes, likes and dislikes, everyday life and relationships. By bringing similarity into existence, the 
mothers are hoping to construct kinship connections between themselves and their child, including other potential children of the future. Following Howell (2003: 465) this production of kinship subjectivity means that the child(ren) and the parents are brought into significant, permanent relationship with one another. It is interesting to note that as part of that process, the donor's role becomes increasingly complex. While it might be assumed that he by virtue of being anonymous would also be completely discounted as a meaningful kin person, the women's accounts suggest a much more multilayered engagement with the part he plays. Whereas his genetic contribution fails to translate into a social relationship, Kim and Nicola, do not render genetic transmittance unimportant. Instead, they renegotiate it, and his contribution becomes a bridge that enables connectedness between them and their child/ren.

In this case, kinship becomes recognised and known within the boundaries of the lesbian mother family. It is worth remembering however, that the clinic route was this couple's second choice. How might the process of working out meaningful connectedness have looked if their first option had been successful? Although we cannot know how this might have been for this couple, the next case is suggestive of how such a route might open up rather different avenues of creating kinship.

\section{Extending kinship}

To Lisa and her partner (who did not take part in the interview) the donor played a key part in the kinship structure they sought to put in place around the child. Being able to identify him was of pivotal importance. In 2002, when they started their process, donors in UK clinics were anonymous and non-identifiable and they therefore felt that they had little option but to arrange the conception informally. They too tried for some time to conceive with the help of a friend who would become part of the child's extended family, but the arrangement came to an end. This meant that they had to rethink the webs of relationships in which they would hope to enrol their child. Rather than going to a clinic, however, they insisted that having an identifiable donor was significant, and so started to search for a new known donor through advertising on a website. They found themselves in the unusual and precarious position of trying to choose a donor based on his personality and social skills among men they had never before met. It was not enough for this couple to know what the donor looked like or what his characteristics were but a social relationships going forward 
into the future mattered too. This was partly because they envisaged him playing a role in their lives for years to come, and partly because they thought that personality and social characteristics may be passed down to the child.

We wouldn't have wanted to conceive with someone we didn't like at all. [...] But also this idea of... you don't know what's passed on. [...] I suppose the mental health aspect of someone was as important as physical health aspects, the social skills and the way the person comes across in a social setting felt as important as their physical characteristics. It didn't have to be a major thing. We only had to spend an hour with him sitting in a pub to know that he felt right. [...] Do you feel comfortable with him?

The accounts deals with genetic kinship quite ambivalently; Lisa does not fully subscribe to the idea that it is important, but is prepared to think that it could matter. Personality, social skills and 'liking someone' are real and everyday experiences and yet fleeting and difficult to define. As such, they speak to an idea of kinship which is no less important but perhaps less tangible and almost ethereal (Mason 2008). They did not render his looks unimportant, but brought in additional kinship dimensions.

Lisa and her partner made active efforts to enrol their daughter not only in a trajectory with themselves, but also with the donor and this different understanding of kinship meant that they engaged in a rather different process of actively bringing kinship into being. For example, they intended to create a book for their child about the process through which she had been born, and arranged to meet up with the donor after birth:

She was about five weeks old and we met up [with the donor]. We just met up for lunch in a pub and we have a photo of him holding her to go in her book. We haven't created one yet, but she'll have it. And so at that point we can say, "Look, here he is [your donor], holding you when you were a baby".

Howell (2001: 213) suggests that taking photos represent an important part of a kinning process that connects child to kin, and to places. The photo allowed the women to create a story of kinship that extended back in time (Howell 2003: 474). Although the donor would not be involved in raising the child, he was seen as an important part of her history. This 
echoes what Smart (2007) has referred to as the process of laying down of memories in families; the meeting signals the process whereby the couple (and the donor) were actively engaged in laying down connections for the child to access, if she chooses to, later in life. Mason and Tipper (2008:455) have noted that children engage in kinship practices by creating a sense of lineage and line of descent that extend long into the past by 'borrowing relational biographies'; they found that children would retrospectively apply their parents' past relationship to make it part of their own connections. This couple can be thought to lend a relational biography to their child prospectively, in case it might be important for her as an adult.

The shared life trajectory mapped out around Lisa's baby was, however, more complex than the arrangement so far suggests. Despite the seemingly personal relationship with the donor, this was a carefully delineated connection. The donor wished to remain at a distance due to the legal framework positioning him as the legal father and he had arranged it so that he could not be traced against his wishes. The couple had a mobile phone number and an email address, but no address. This meant that he played a very limited part in the child's active network of kin. Interestingly, however, while the donor remained relatively anonymous himself, he had formed a network among the families of children created through his donations, echoing to some extent the formation of the US Donor Sibling Registry (Freeman et al. 2009, Hertz and Mattes 2011). Lisa suggested that the donor's motive for doing so was to communicate about the children's health. Through this, Lisa was in touch with parents whose children were genetically related to their daughter:

We're interested in knowing about them, and in fact we are now in email contact with another lesbian couple who have two children through him. [...] I think it will be good for [our daughter] when she starts asking those questions about the donor, to say he helped other people and these are some of the other kids. [...] There is a biological extended family for her through that, although she doesn't have that extended family with the donor personally perhaps.

Through being part of a network of families, Lisa and her partner made kinship known in ways that went beyond not only the boundaries of their own family but also beyond the donor himself. Apart from the shared biogenetic connection with these other families, there was also a sense that the parents' process of becoming parents was so unusual that other 
people who had conceived in this same way were connected by virtue of having gone through the same process. This network, which was partly about sharing genes and partly about sharing experiences, formed ties of connections for both the daughter as well as the parents thus echoing findings made in the field of adoption (Howell 2001: 214). Interestingly, though, there was a possible connection with multiple families and children, and yet with no family in particular. The boundaries of these affective ties, now and in the future, were unknown as families might exit or enter, and with the birth of more children new members might join.

The cases discussed so far illustrate two very different ways of imagining how a child might be enrolled in a shared trajectory with those perceived to constitute his or her family, suggesting that kinship as a relationship can be moulded to flex and stretch around the family as it emerges. In both cases couples have had to revisit these ideas as the course of their reproductive journeys changed. However, that revisiting has happened before any child was conceived. To do so after the birth of a child might be a rather more challenging prospect as the child by then is already enrolled in various relationships. Although we cannot know the future of these couples, it is important to ask how such a challenge might be dealt with. My third case, a couple called Wendy and Penny, is illustrative of how changes in life might give rise to kinship quandaries.

\section{Renegotiating kinship}

Wendy and Penny had a daughter together with a donor friend. The women were financially responsible for the child, the main carers and her day to day parents, but the child's father had contact time. They had created a reproductive relationship that spanned the lives of three individuals and two households. In contrast to Lisa, where the limits of possible family connections remained undefined, this kinship network was specific and exclusive to the mothers and to the donor father, who had no other offspring.

The issue that brought about change was a discussion about having siblings, as Wendy and Penny wanted a second child. Although they lived a separate and autonomous life, they were in the precarious position of being unable to have another child without the consent of the donor father. However, things had changed for him since the daughter was born and he did not want another child; to their utter disappointment he refused. The couple found the 
idea of having a second child by someone else quite unimaginable as illustrated in the account below, and felt immensely powerlessness and frustrated:

It felt like there was no other option. At that stage, for us, it was him or no more children. [...] Because it felt at that stage as though we had our first option, our best option, for [our daughter]. And how would you do anything else for your next child? [...] And it just felt like that was just wrong. (Wendy)

The account highlights the moral implications perceived to be embedded in the reproductive choice of having an involved donor father (Almack 2006, Ryan-Flood 2005) but also how the situation gave rise to a crisis of kinship. The arrangement was such that the donor (father) as well as the birth and non-birth mother had reproduced (Strathern 1995:356); Wendy, Penny and the donor had enrolled their first-born in a kinship structure that overlapped all of them. The kinning of a second child would have to look different; their account is framed around the idea that it would be impossible to bring that child into the same web of connectedness as the first-born. It is also framed around the notion that fairness should characterise sibling relationships, and that not being able to put the same relationship in place for both siblings raised could be problematic. Again, producing sameness emerges as a central idea in kinship thinking, and not being able to put similarity in place was extraordinarily unsettling and anxious provoking. This couple felt unable to negotiate having a second child if it meant departing from sameness, as they perceived it as impossible to tie their children and their family together as kin in these circumstances.

Wendy and Penny started to renegotiate the meaning of kinship, completely transforming the way they imagined and valued what it meant to be connected. This took them on a journey of deep reflexivity. Adoption, the couple first thought, would allow them to have a second child without the involvement of their friend and yet without having willingly deprived that child of what they saw as essential of good upbringing - a father. But then Wendy says:

Very quickly we kind of both got to this point of, hang on a minute, are we thinking about adoption because we almost want somebody else to be the bad guy? [...] And aren't we selling ourselves short as parents here. [...] We provide [our daughter] with all of her emotional security. Her dad provides her with something 
good but it's actually something extra and additional to what we give her. It's not essential.

Wendy and Penny brought themselves to a point where they started to renegotiate the meaning of kinship; as with Kim and Nicola, they became fully focused on the relationships within the lesbian mother family. Identifying these connections as the important ones, the couple rejected adoption in favour of having another birth child. Donor conception was perceived to offer a better chance of creating overlapping life trajectories:

If we go down the route of adoption there potentially are huge differences between [our daughter] and that child. They share no blood or genetics at all, which is a big thing, to share nothing kind of genetically in common. Their start in life has been totally different. [...] And we sort of came back down to, actually if it is possible, we want to have another child from the start. (Wendy) Because it was about that shared history and shared experience. (Penny)

Donor conception was perceived to provide a better chance of creating similarity compared to adoption. Wendy explains:

Well, I'm [our daughter's] birth mum and I'm this baby's birth mum. [...] It's that commonality of experience right from the start really. Rather than, you know, genetically they could be completely different from each other, of course they could. [...] But it's that fact of [our daughter] knows she grew in my tummy. She knows that I gave birth to her upstairs, in the bedroom upstairs. She knows that I breast fed her. She knows that she used to have a bath with mummy Penny every night. And it's that stuff really.

Wendy highlights the importance of a biogenetic relationship between the siblings, but more so she emphasises a kinning process that revolves around family practices (Morgan 1996). This echoes the idea that 'kinship relates people together in a shared temporal and spatial universe, and kinned places are central to the formation of identity and personhood' (Howell 2003: 472). Wendy and Penny imagined that sharing a rootedness in time and space would create bonds of belonging and affinity between the children. Additionally, Wendy 
perceived family resemblances, albeit mysterious, to create an important commonality in feeling:

[Our daughter] has got cousins, all on my side [...] And certainly one of those cousins, a little boy, he's nearly one year. And he's got very, very similar eyes to [her]. And she sees him and she goes, "Oh, he's got the same eyes as me." [...] Me and my siblings don't look alike, there's five of us and we don't look alike. But there is commonality amongst us all. And there is commonality amongst our children. And I think that that is more likely to be there if there's a genetic link and a bond right from the start.

By constructing a series of relationships of sameness (in e.g. life trajectory, genetic relationships, physical traits, care and family practices), the mothers worked at enrolling a second child by a different donor into meaningful connectedness with the family (Howell 2001: 206). Framed by their hopes, fears and imaginings for the future, they settled on a new version of kinship that allowed them to bring into existence a new set of affinities. The account displays a remarkably complex engagement with both genetic and social tropes of kinship in the process of renegotiating meaningful connections. The importance of genetics and creating sameness were not rendered unimportant but, rather, kinship mutated into a new form.

\section{Discussion}

I have used original data from the field of donor conception to explore Mason's idea that kinship belonging is not something that just 'is', but it is something that very carefully is brought into existence, known and engaged with through various strategic, bodily, practical, personal, affective and familial practices as part of everyday life. The way in which the mothers in my study 'worked at' enrolling their child/children in a relationship of kinship highlighted how the criteria for kinship can shift and change. Whereas the first case allow us to experience kinship as a relationship that is known within the nuclear family, the second case illustrates how quite a different set of relationships can be activated and rendered meaningful and still be understood as those of kin. The third case, interestingly, illustrates that various meaningful connections can also shift over time within the same family as life takes a new turn, and yet remain centred on the importance of being connected. 
I argue that this suggests that we need to understand kinship as a discourse and relationship that has an extraordinary capacity to fold and stretch into different shapes. It is not only the case that it can change and mutate over time as people find themselves in a situation where what matters in kinship must be revisited. But much like clay, it emerges as something that can be manufactured into numerous meaningful shapes and forms, and yet still be recognised as the same thing, i.e. kinship relationality. Of course, donor conception brings with it particular challenges, and so does lesbian motherhood. However, rather than seeing these mothers' stories as extraordinary, I want to suggest that they draw on a kinship discourse that in and of itself already lends itself to complex and multilayered interpretations. Through its malleable and elastic character, this relationship presents hugely variable qualities. The meaning of genes, similarity, motherhood, fatherhood, personality, characteristics, aptitudes, physicality, pregnancy, feelings, space, practices, time, fairness and resemblances can be renegotiated, revisited and even transformed, and yet still all be used to signal connectedness. Thereby, we can emphasise the importance of some relations whilst discounting others in a way that fits the family we live with and also cope with an unpredictable future.

Underscoring these women's varying ways of engaging with kinship is the crucial importance attached to being connected (Smart 2007). This is perhaps best illustrated by the fact that they are so thoughtfully and carefully trying to avoid denying the child any form of kinship that might be important to him or her later in life (notwithstanding that that form of kinship might not be one that the parents themselves sign up to). They are not sure what particular versions of kinship go to make up a person and they are also unsure about how certain forms of relationships might count in the future. But they want to make sure that a mix of different aspects that can count as kin are in place in case any one of them might turn out to be important. These practices are attempts to ensure that their child will feel embedded in some kind of kinship network in the future. The perceived success or failure to do so generated significant emotional responses spanning powerlessness, regret, disappointment, concern and anxiety as well as pleasure, amusement and delight. The narratives are suggestive of a cultural discourse of a need for rootedness (Edwards 2000) and that we live in a culture in which identity remains firmly rooted in kinship (Kramer 2011). 
These findings are important for the field of donor conception of course, but also have significant implications for understanding and conceptualising kinship in much a broader sense. The idea that kinship has an extraordinary capacity to mould into the shape that we give it, and also to shift and change over time, has implications for how we empirically learn to recognise family connections in research, and practice. It is possible to imagine that similar kinship questions emerge in a variety context of family contexts, e.g. divorce, death, family breakdown, step-parenting, adoption and fostering. My research suggests that in order to understand how kinship matters in personal life we need not only recognise the importance of kinship in everyday life but also develop a complex and multilayered understanding of kinship, recognising that meaningful connections in personal life might go beyond conventional tropes of kinship. As such, it also poses serious questions about the emphasis we place on genetic relatedness in policy, and practice.

\section{References}

Almack, K. (2006) 'Seeking sperm: Accounts of lesbian couples' reproductive decisionmaking and understandings of the needs of the child', International Journal of Law, Policy and Family, 20(1):1-22

Almeling, R. (2007) 'Selling genes, selling gender: Egg agencies, sperm banks, and the medical market in genetic material', American Sociological Review, 72(3): 319-340

Blyth, E. et al. (2009) 'The role of birth certificates in relation to access to biographical and genetic history in donor conception', International Journal of Children's Rights, 17: 207233

Brannen, J. et al. (2004) Working and Caring over the Twentieth Century: Change and Continuity in Four-Generation Families, Basingstoke: Palgrave Macmillan.

Daniels, K. et al (1995) Telling donor insemination offspring about their conception: The nature of couples' decision-making, Social Science of Medicine, 40(9): 1213-1220

Davies, H. (2011) 'Sharing surnames: Children, Family and Kinship', Sociology, 45(4): 554-569

Donovan, C. and Wilson, A. (2008) Imagination and integrity: Decision-making among lesbian couples to use medically provided donor insemination, Culture, Health and Sexuality, 10(7): 649-665

Edwards, J. (2000) Born and Bred: Idioms of Kinship and New Reproductive Technologies in England. Oxford: Oxford University Press. 
Finch, J. (2008) 'Naming names: Kinship, individuality and personal names', Sociology, 42(4):709-725

Finch, J. and Mason, J. (1993) Negotiating Family Responsibilities. London: Tavistock/Routledge.

Finch, J. and Mason, J. (2000) Passing on: Kinship and Inheritance in England. London: Routledge.

Firth, R. et al. (1970) Families and Their Relatives: Kinship in a Middle-Class Sector of London: An Anthropological Study. New York: Humanities Press.

Franklin, S. (1997) Embodied Progress. A Cultural Account of Assisted Conception. London: Routledge.

Freeman, T. et al. (2009) 'Gamete donation: parents' experiences of searching for their child's donor siblings and donor', Human Reproduction, 24(3):505-516

Golombok, S. and Badger, S. (2010) 'Children raised in mother-headed families from infancy: a follow-up of children of lesbian and single heterosexual mothers, at early adulthood', Human Reproduction, 25(1): 150-157

Golombok, S. et al. (1997) 'Children raised in fatherless families from infancy: Family relationships and the socioemotional development of children of lesbian and single heterosexual mothers, Journal of Child Psychology and Psychiatry, 38(7): 783-791

Graham, H. (2007) Unequal Lives: Health and Socio-Economic Inequalities. Maidenhead: Open University Press.

Haimes, E. (1992) 'Gamete donation and the social management of genetic origins', pp. 119147 in M. Stacey (ed) Changing Human Reproduction. Social Science Perspectives. London: Sage.

Hayden, C. (1995) 'Gender, genetics and generation: Reformulating biology in lesbian kinship', Cultural Anthropology, 10(1):41-63

Hertz. R. and Mattes, J. (2011) 'Donor-shared siblings or genetic strangers: New families, clans, and the internet', Journal of Family Issues, 32(9):1129-1155

Howell, S. (2001) 'Self-conscious kinship: Some contested values in Norwegian transnational adoption', pp. 203-223 in S. Franklin and S. McKinnon (eds) Relative Values: Reconfiguring Kinship Studies. Durham and London: Duke University Press. 
Howell, S. (2003) 'Kinning: The creation of life trajectories in transnational adoptive families, Journal of the Royal Anthropological Institute, 9:465-484

Kramer, A-M. (2011) 'Kinship, affinity and connectedness: Exploring the role of genealogy in personal lives', Sociology 45(3):379-395

Lashewicz, B. et al. (2007) 'Equity matters: Doing fairness in the context of family caregiving', Canadian Journal on Aging, 26(1): 91-102

Lieblich, A. et al. (1998) Narrative Research. Reading, Analysis and Interpretation. London: Sage.

Luce, J. (2010). Beyond Expectation. Lesbian/Bi/Queer Women and Assisted Conception. Toronto: University of Toronto Press.

Marre, D. and Bestard, J. (2009) 'The family body: Persons, bodies and resemblance', pp. 6478 in J. Edwards and C. Salazar (eds) European Kinship in the Age of Biotechnology. Fertility, Reproduction and Sexuality series. Oxford: Berghahn Books.

Mason, J. (2008) 'Tangible affinities and the real life fascination of kinship'. Sociology, 42(1): $29-45$

Mason, J. and Tipper, B. (2008) 'Being related: How children define and create kinship', Childhood 15(4): 441-460

Melhuus, M. and Howell. S. (2009) 'Adoption and assisted conception: One universe of unnatural procreation. An examination of Norwegian legislation', pp. 144-161 in J. Edwards and C. Salazar (eds) European Kinship in the Age of Biotechnology. Fertility, Reproduction and Sexuality series. Oxford: Berghahn Books.

Miles, M. and Huberman, A. (1994) Qualitative Data Analysis. An Expanded Sourcebook. $2^{\text {nd }}$ ed. London: Sage Publications.

Morgan, D. (1996) Family Connections. An Introduction to Family Studies. Cambridge: Polity Press.

National Institute for Clinical Excellence (NICE) (2004) 'New NHS guidelines on fertility treatment'. Available at <www.nice.org.uk> (Accessed 3 November 2006)

Nordqvist, P. (2010) "Out of sight, out of mind'. Family resemblances in lesbian donor conception', Sociology, 44(6): 1128-1144

Nordqvist, P. (2011) 'Dealing with sperm: comparing lesbians' clinical and non-clinical donor conception processes. Sociology of Health and IIIness, 33(1): 114-129 
Nordqvist, P. (2012a) ‘Origins and originators: Lesbian couples negotiating parental identities and sperm donor conception', Culture, Health and Sexuality, 14(3): 297-311 Nordqvist, P. (2012b) “I don't want us to stand out more than we already do': Complexities and negotiations in lesbian couples' accounts of becoming a family through donor conception', Sexualities, 15(5-6): 644-661

Rosser, C. and Harries, C. (1965) The Family and Social Change: Family and Kinship in a South Wales Town. London: Routledge.

Ryan-Flood, R. (2009) Lesbian Motherhood. Gender, Families and Sexual Citizenship. Basingstoke: Palgrave Macmillan.

Smart, C. (2007) Personal Life: New Directions in Sociological Thinking. Cambridge: Polity. Strathern, M. (1992) Reproducing the Future. Essays on Anthropology, Kinship and the New Reproductive Technologies. Manchester: Manchester University Press.

Strathern, M. (1995) 'Displacing knowledge. Technology and the consequences for kinship', pp. 346-363 in F. Ginsburg and R. Rapp (eds) Conceiving the New World Order. The Global Politics of Reproduction. Berkeley: University of California Press.

Strathern, M. (2005) Kinship, Law and the Unexpected. Relatives Are Always a Surprise. Cambridge: Cambridge University Press.

Weeks, J. et al. (2001) Same Sex Intimacies: Families of Choice and Other Life Experiments. New York: Routledge.

\section{Acknowledgements}

This research was funded by the Economic and Social Research Council Doctoral Award [PTA-031-2006-00503], the British Federation of Women Graduates Funds for Women Graduates Foundation Main Grant and the British Sociological Association Support Fund. Special thanks to Jennifer Mason and Lindsay Manning for comments on an earlier draft, and to the anonymous reviewers for insightful and helpful suggestions.

\section{Biography}

Petra Nordqvist is a lecturer in Sociology at the University of Manchester and is affiliated with the Morgan Centre for the Study of Relationships and Personal Life. Her work focuses on reproductive technologies, kinship, and sexualities and her publications include, for example, "Choreographies of sperm donations: Dilemmas of intimacy in lesbian couple donor conception', Social Science and Medicine, (2011). She is currently working on an ESRC 
funded project exploring non-genetic kinship in the context of assisted conception and how parents and grandparents of donor conceived children negotiate processes of disclosure. 